\title{
Superior Pubic Ramus
}

National Cancer Institute

\section{Source}

National Cancer Institute. Superior Pubic Ramus. NCI Thesaurus. Code C132415.

The portion of the pubic ramus that lies between the body of the ilium and the inferior pubic ramus. 